\title{
Treatment Options and Follow-Up among Iraqi Patients with Breast Carcinoma
}

\author{
Nada A. S. Alwan and Mena M. Shawkat
}

\begin{abstract}
Breast cancer ranks the first among the Iraqi population and the leading cause of cancer related female mortality. In addition to the barriers that impede early detection of that cancer other major challenges include the capacity for effective multimodality treatment.

Aim: To review and follow up a sample of Iraqi female patients diagnosed with breast cancer in a main referral center; recording their clinico-pathological characteristics, the offered treatment options and the rate of recurrence.

Material and Methods: This retrospective study analyzed the clinical and pathological characteristics of 230 Iraqi female patients histologically diagnosed with breast carcinoma who had reliable valid data related to their demographic, clinical and tumor pathological status. The studied parameters included the age of the patient, marital status, parity, age at first delivery, occupation, history of lactation and hormonal intake, family history of breast and any other cancer, histological type, tumor grade and clinical stage. Hormone receptors (Estrogen and Progesterone) and HER2 over expression contents of the primary tumors were evaluated immunohistochemically. The offered treatment options included surgery, chemotherapy, radiotherapy, hormonal and biological targeted therapy. The rate of recurrence was evaluated after a follow-up period of three years.
\end{abstract}

Results: Only $3.5 \%$ of the patients were under the age of 30 years while 39.1\% were aged 50 years and over. About $84 \%$ were married, $11.3 \%$ were nulliparous, $24.9 \%$ had their first delivery before the age of 20 years and $56.9 \%$ were housewives. History of lactation was reported in $\mathbf{6 0 . 4 \%}$, whereas history of breast cancer was registered in $17.4 \%$. The most common histological type of breast carcinoma was the infiltrative ductal $(86.5 \%)$, well differentiated carcinomas were diagnosed in only $5.2 \%$. The rates of positive ER, PR and HER2 tumor contents were $68.3 \%, 65.7 \%$ and $29.6 \%$ respectively. Overall $8.3 \%$, $4.3 \%, 39.6 \%$ and $7.8 \%$ of the patients were diagnosed at stages I, II, III and IV respectively. Surgery was the primary treatment modality prescribed to the vast majority $(96.1 \%)$ of the patients; $88.2 \%$ of those underwent modified radical mastectomy and only $3.6 \%$ had breast conservative surgery. Whereas $91.7 \%$ received chemotherapy, radiotherapy, hormonal and biological therapy were applied on $65.7 \%$, $63.5 \%$ and $27.4 \%$ respectively. Recurrence of breast carcinoma three years following treatment was displayed among 9.7\%; displaying significant direct association with the clinical stages of the disease $(p<.05)$.

Conclusions: Breast cancer is still diagnosed at relatively advanced stages at the time of first presentation in Iraq; requesting radical mastectomy. Early detection represents the principal approach to control breast cancer in the near future. Regular long-term follow up through multidisciplinary tumor boards is mandatory to monitor response to therapy and recurrence.

Published on March 24, 2020

N. A. S. Alwan (Corresponding Author) is M.D., M.Sc., Ph.D., Professor of Pathology, Founder, National Cancer Research Center, University of Baghdad, Iraq. (e-mail: nadalwan@yahoo.com)

M. M. Shawkat is MB, ChB. Department of Pathology, Medical College, University of Baghdad, Iraq.
Index Terms-Breast Carcinoma, Follow-up, Iraqi Patients, Options, Treatment.

\section{INTRODUCTION}

Whereas breast cancer is the most prevalent malignancy among women worldwide [1], in Iraq it ranks the first among the population and the leading cause of cancer related female mortality [1], Numerous studies from Iraq indicated that up to the present time a considerable rate of female patients still present with breast cancer at younger age groups with more advanced stages and aggressive tumor biological profiles compared to their western counterparts [3]- [9]; ultimately leading to unfavorable prognosis.

It has been reported that breast cancer is etiologically, genetically and histologically heterogeneous [10]. The World Health Organization has clearly documented that early detection of breast cancer when linked with adequate therapy could significantly reduce death from the disease in developing countries [11]. In Iraq, a national program for early detection of breast cancer has been initiated since 2001 [3]-[5], [8], [12]. Adding to the barriers that constantly impede early diagnosis of that cancer in the country, which have been comprehensively illustrated in earlier studies [13]- [19], other major challenges facing that project include the lack of evidence-based protocol guidelines associated with the limited capacity for effective multimodality treatment [4], [8], [12], [16], [20].

The dilemma of inadequate poorly accessible health services which leads to the crippling out-of-pocket healthcare expenditures contribute significantly to the low survival from the disease in low- and middle-income countries [21], [22]. Improving access to multimodality treatment of breast cancer should involve surgery, chemotherapy, adjuvant hormone and radiotherapy. In general, the choice of treatment is determined by many factors including the pathological features of breast cancer, the demographical and clinical characteristics of the patients and the risks of recurrence. The latter demands regular follow up to diagnosis any loco-regional relapse promptly. Limited research has been published in the literature of developing countries regarding the treatment options in the management of breast cancer and the follow-up of the affected patients [22]- [25].

This study was designed to follow up a sample of Iraqi patients diagnosed with breast cancer at a major tertiary health care center in Baghdad; recording their clinicopathological characteristics, the offered treatment options and the rate of recurrence. 


\section{MATERIALS AND MethodS}

This retrospective study analyzed the clinical and pathological characteristics of 230 Iraqi female patients diagnosed with breast cancer. The studied variables were registered from the information system data base of the National Cancer Research Center, Baghdad University and the case sheet records of the Referral Center for Early Detection of Breast Tumors, Oncology Teaching Hospital in Baghdad throughout the year 2019.

Inclusion criteria comprised all female patients with histopathologically confirmed diagnosis of invasive breast carcinoma who have reliable valid follow up data related to their demographic, clinical and pathological status (for three years). Cases with non-invasive in situ carcinoma and those with missing information were excluded. Each patient in this study completed a written consent prepared and approved by the Ethical Committee of the National Cancer Research Center in accordance with the ethical standards of the declaration of Helsinki; allowing clearly the utilization of their relevant information for the purpose of research studies.

Demographic, clinical and pathological parameters included the age of the patient at the time of diagnosis, marital status, parity, age at first delivery, occupation, history of lactation and hormonal intake (for a minimum period of 6 months), family history of breast or any other cancer, WHO histological typing of breast carcinoma [26], tumor grade (following modified Nottingham Bloom Richardson) [27] and the clinical stage of the disease at presentation (defined according to the UICC TNM Classification System) [28]. Assessment of Estrogen and Progesterone receptors (ER, PR) and HER2 over expression contents of the primary tumors was carried out by Immunohistochemical (IHC) staining of the formalin fixed paraffin-embedded tissue blocks containing the breast cancer specimens utilizing (Dako) kits and specific monoclonal antibodies

The offered therapeutic options included the type of treatment (surgery, chemotherapy, radiotherapy, hormonal and biological). Assessment of the rate of recurrence after a follow-up period of three years was carried out through reviewing the patient's history, clinical examinations, imaging investigations and laboratory tests; recording the relationship with the clinical stages of breast cancer at the time of first presentation.

Statistical analysis of the studied variables was carried out using Statistical Package for Social Sciences (SPSS) version 25. Categorical data were presented by frequencies and percentages. Chi square test was used to assess the association between the recurrence of breast carcinoma and the stage of disease at diagnosis. A level of $\mathrm{P}$ value less than 0.05 was considered significant.

\section{RESUlts}

TABLE I: THE DEMOGRAPHIC, CLINICAL AND TUMOR PARAMETERS

\begin{tabular}{|c|c|c|}
\hline Parameters & $\mathrm{N}$ & $\%$ \\
\hline \multicolumn{3}{|l|}{ Age (years) } \\
\hline$<30$ & 8 & 3.5 \\
\hline $30-49$ & 132 & 57.4 \\
\hline$=/>\mathbf{5 0}$ & 90 & 39.1 \\
\hline \multicolumn{3}{|l|}{ Marital status } \\
\hline Currently married & 194 & 84.3 \\
\hline Single & 25 & 10.9 \\
\hline Divorced or widowed & 11 & 4.8 \\
\hline \multicolumn{3}{|l|}{ Parity $(n=204)$} \\
\hline No children & 23 & 11.3 \\
\hline $1-3$ & 60 & 29.4 \\
\hline$>3$ & 121 & 59.3 \\
\hline \multicolumn{3}{|l|}{ Age at $1^{\text {st }}$ childbirth $(\mathrm{n}=181)$} \\
\hline$<20$ & 45 & 24.9 \\
\hline $20-29$ & 97 & 53.6 \\
\hline$\geq \mathbf{3 0}$ & 39 & 21.5 \\
\hline \multicolumn{3}{|l|}{ Occupation } \\
\hline Housewife & 131 & 56.9 \\
\hline Employee & 88 & 38.3 \\
\hline Retired & 9 & 3.9 \\
\hline Student & 2 & 0.9 \\
\hline \multicolumn{3}{|l|}{ History of Lactation } \\
\hline Yes & 139 & 60.4 \\
\hline No & 91 & 39.6 \\
\hline \multicolumn{3}{|l|}{ Family History of Breast Cancer } \\
\hline Yes & 40 & 17.4 \\
\hline No & 190 & 82.6 \\
\hline \multicolumn{3}{|l|}{ Family History of Other Cancers } \\
\hline Yes & 24 & 10.4 \\
\hline No & 206 & 89.6 \\
\hline \multicolumn{3}{|l|}{ Histopathological Type } \\
\hline Invasive ductal carcinoma & 199 & 86.5 \\
\hline Invasive lobular carcinoma & 16 & 6.9 \\
\hline Mixed & 6 & 2.6 \\
\hline Others & 9 & 3.9 \\
\hline \multicolumn{3}{|l|}{ Tumor Grade } \\
\hline Well Differentiated & 12 & 5.2 \\
\hline Moderately Differentiated & 162 & 70.4 \\
\hline Poorly Differentiated & 56 & 24.3 \\
\hline \multicolumn{3}{|l|}{ Estrogen Receptor } \\
\hline Positive & 157 & 68.3 \\
\hline Negative & 73 & 31.7 \\
\hline \multicolumn{3}{|l|}{ Progesterone Receptor } \\
\hline Positive & 151 & 65.7 \\
\hline Negative & 79 & 34.3 \\
\hline \multicolumn{3}{|l|}{ HER2 Over Expression } \\
\hline Positive & 68 & 29.6 \\
\hline Negative & 162 & 70.4 \\
\hline
\end{tabular}

Table I illustrates the demographic, clinical and tumor characteristics of the studied patients. The peak age frequency was noted among the age period (30-49 years); only $3.5 \%$ were under the age of 30 years while $39.1 \%$ were aged 50 years and over. Approximately $84 \%$ of the patients were married, $11.3 \%$ were nulliparous, about $25 \%$ had their first delivery before the age of 20 years and $57 \%$ were housewives. History of lactation was reported in $60.4 \%$, whereas history of breast cancer and other cancers were registered in $17.4 \%$ and $10.4 \%$ respectively. The most common histological type of breast carcinoma was the infiltrative ductal $(86.5 \%)$ followed by the lobular $(6.9 \%)$. Well differentiated carcinomas were diagnosed in only $5.2 \%$ while the majority (70.4\%) was graded as moderately differentiated. Positive ER, PR and HER2 overexpression contents of the primary carcinomas were confirmed by IHC assays in $68.3 \%, 65.7 \%$ and $29.6 \%$ respectively. 
TABLE II: CliniCAL STAGES OF BREAST CANCER AT THE TIME OF DIAGNOSIS

\begin{tabular}{|c|c|c|c|c|}
\hline Stage & & $N(n=230)$ & $(\%)$ & Total N (\%) \\
\hline I & & 19 & 8.3 & $19(8.3)$ \\
\hline \multirow{2}{*}{ II } & IIA & 66 & 28.7 & \multirow{2}{*}{$102(44.3)$} \\
\hline & IIB & 36 & 15.6 & \\
\hline \multirow{3}{*}{ III } & IIIA & 58 & 25.2 & \multirow{3}{*}{$91(39.6)$} \\
\hline & IIIB & 11 & 4.8 & \\
\hline & IIIC & 22 & 9.6 & \\
\hline IV & & 18 & 7.8 & $18(7.8)$ \\
\hline Total & & 230 & 100 & $230(100)$ \\
\hline
\end{tabular}

Clinical staging of the patients with breast carcinoma in this study revealed that overall $8.3 \%$ of the patients (19 cases) presented at stage I, whereas $44.3 \%$ (102 cases), $39.6 \%$ (91 cases) and 7.8\% (18 cases) were diagnosed in stages II, III and IV respectively (Table II). Stage II was sub classified into IIA and IIB (28.7\% and $15.6 \%$ of total respectively). On the other hand, stage III was further subcategorized into IIIA, IIIB and IIIC (25.2\%, 4.8\% and $9.6 \%$ of total respectively).

TABLE III: THE OFFERED TREATMENT OPTIONS IN BREAST CANCER MANAGEMENT

\begin{tabular}{|c|c|c|}
\hline Treatment Modality & $\overline{\mathbf{N}}$ & $\%$ \\
\hline Surgery* & 221 & 96.1 \\
\hline Chemotherapy & 211 & 91.7 \\
\hline Radiotherapy & 151 & 65.7 \\
\hline Hormonal & 146 & 63.5 \\
\hline Biological & 63 & 27.4 \\
\hline
\end{tabular}

Treatment options were instructed by the examining surgeons and oncologists according to each individual condition (Table III). Surgery was carried out on 221 patients $(96.1 \%)$; the majority $(88.2 \%)$ underwent modified radical mastectomy and only $3.6 \%$ (8 patients) had breast conservative surgery. Two-hundred and eleven patients (91.7\%) received Chemotherapy while Radiotherapy sessions were designed for 151 cases $(65.7 \%)$. According to the results of IHC, hormonal therapy (Tamoxifen and Aromatase inhibitors) was offered as an adjuvant treatment option in 146 patients with ER and/or PR positive tumor contents $(63.5 \%)$; whereas Herceptin was prescribed to 63 patients $(27.4 \%)$ who had HER2 positive results.

TABLE IV: ASSOCIATION OF RECURRENCE WITH BREAST CANCER STAGES

\begin{tabular}{|c|c|c|c|c|}
\hline \multicolumn{2}{|c|}{$\begin{array}{l}\text { CLINICAL BC STAGE } \\
(\mathrm{TN}=230) \\
\mathbf{N}(\%)\end{array}$} & \multicolumn{2}{|c|}{$\begin{array}{l}\text { RECURRENCE } \\
(\mathrm{TN}=217) * \\
\text { Yes No } \\
\text { N (\%) N (\%) }\end{array}$} & \multirow{2}{*}{$\begin{array}{l}\text { TOTAL** } \\
\text { N (\%) } \\
19(08.3) \\
\end{array}$} \\
\hline I $19(8.3)$ & & 0 & $19(100)$ & \\
\hline \multirow{2}{*}{ II 102 (44.3) } & IIA $66(28.7)$ & 0 & $66(100)$ & \multirow{2}{*}{$\begin{array}{l}102 \\
(44.3)\end{array}$} \\
\hline & IIB $36(15.6)$ & $2(5.6)$ & $34(94.4)$ & \\
\hline \multirow{3}{*}{ III 91 (39.6) } & IIIA $58(25.2)$ & $5(8.6)$ & $53 \quad(91.4)$ & \multirow{3}{*}{91 (39.6) } \\
\hline & IIIB $11(4.8)$ & $2(18.2)$ & $9(81.8)$ & \\
\hline & IIIC $22(9.6)$ & $6(27.3)$ & $16(72.7)$ & \\
\hline \multicolumn{2}{|l|}{ IV $18(7.8)$} & $6(33.3)$ & $12(66.7)$ & $18(07.8)$ \\
\hline \multicolumn{2}{|l|}{ TOTAL } & $21(9.7)$ & $196(90.3)$ & $230(100)$ \\
\hline
\end{tabular}

*Total number of studied cases; 13 out of 230 cases $(5.7 \%)$ had missing information regarding the recurrence state

**Chi Square statistic is 16.2252 . The $\mathrm{p}$ value is .00102 . The result is Significant at $\mathrm{p}<.05$.

Overall, recurrence of breast carcinoma following treatment was displayed in 21 patients $(9.7 \%)$ during the three-year follow up period of the study. The relationship between the clinical stage of breast cancer at the time of presentation and the recurrence state was significant at $\mathrm{p}<$
.05. (Table IV). Whereas no patient diagnosed at stage I and IIA had any recurrence, $5.6 \%, 8.6 \%, 18.2 \%$ and $27.3 \%$ of patients presenting in stages IIB, IIIA, IIIB and IIIC respectively had positive relapse of the disease. On the other hand, recurrence was observed in one third of the patients diagnosed with stage IV ( 6 out of 18 cases).

\section{DISCUSSION}

The demographic and clinical profiles of breast cancer in this study clearly illustrate the prevalence among premenopausal women; where the peak age frequency is noted in the middle aged groups. That finding was emphasized in numerous studies from Iraq [2]-[6], [8], [9], [12], [16]-[19]; and other developing countries [11], [21][25]; probably reflecting the younger age pyramid of the populations in these regions of the world compared to the developed countries where breast cancer is typically a disease of postmenopausal women. A comparative study on the characteristics of breast cancer in Iraq and the United Kingdom revealed that Iraqi patients were significantly younger [1]; justifying the initiation of screening programs for that type of cancer earlier [16], [18]- [22], [29].

Contrary to the clinical presentation of breast cancer reported in western studies [30]- [32] our data indicate that the majority of breast cancer in Iraq affect married multiparas women; interestingly, one quarter have delivered their first child in their teen ages and about two thirds had history of lactation. These results confirm the findings recorded in earlier Iraqi surveys [3], [4], [6], [16], [18], [19]; supporting the hypothesis that breast cancer is genetically heterogeneous and that racial disparities are reflected in the biological behavior of the disease in different societies [4], [33], [34]. The relatively high family history of breast cancer observed in this study and other published series from Iraq [3], [6], [16], [29], [35] recommend active promotion of public awareness and regular follow up among the target female population to identify promptly the high risk groups for breast cancer control.

The treatment options were modified in this study according to the tumor characteristics and the clinical stage at diagnosis. Pathologically, the histological and IHC profiles correspond to those reported in previous studies from Iraq; where moderately invasive ductal carcinomas predominate [3]- [5], [7]- [9] Compared to research on western patients, the lower rates of hormone receptor positive tumor contents coupled by the significantly higher HER2 over expressions among Iraqi patients reflect the predilection towards more aggressive behavioral forms of breast cancer [3], [4], [7], [9], [36], [37]. The dilemma of late stage at breast cancer presentation in Iraq and other developing countries has been the focus of many studies [3][9] which addressed several patient and health systemmediated barriers to early detection of the disease aiming to develop appropriate control strategies [11]- [24], [38], [39]. The lack of public education about breast health care in lowand middle- income countries reflected by the remarkable gaps in the knowledge regarding breast cancer urged the necessity to establish protocol guidelines for early detection and treatment of the disease stratified according to the level of available resources [16], [40]. 
In addition to the lack of access to affordable quality multimodality treatment options, the high mortality from breast cancer in developing countries is significantly linked to the stigma and associated societal implications of mastectomy which discourage women from seeking prompt medical care [22], [24]. Surgery as the primary treatment modality was prescribed to the majority of the patients in this study $(96 \%)$. A critical review on mastectomy practice documented that although it is no longer considered a firstline choice for treating all breast cancers; nevertheless, it is still adopted as a principal procedure in the management [41]. It is regrettable to note that modified radical mastectomy is the standard surgery in Iraq [3], [7], [20] and other developing Arab countries [21]- [23]. where most of the patients are detected at late stages and the established radiotherapy centers have limited capacity for sophisticated conservative approaches [42]. Significantly higher rates of practicing breast conserving surgery are reported in studies from developed countries [42], [43]. It was found that in the presence of standard radiotherapy facilities there was no significant difference in survival among patients who underwent mastectomy versus those who had breast conservative surgery although many preferred mastectomies due to the fear of recurrence [43].

As invasive breast carcinomas require postoperative radiotherapy, $65.7 \%$ of the patients in this study were offered that treatment option in well-equipped units free of charge. Nevertheless, during the period of the study $8.8 \%$ did not continue treatment. Excluding financial causes, discontinuation of breast cancer therapy after initiation is often attributed to the associated side effects, long waiting lists or psychological factors [21]- [24], [44]. In a literature analysis on the trends in the management of breast cancer it was displayed that modern radiation therapy is available only in select centers in the Arab countries; recommending investment in technical equipment and human resources to overcome that shortage and its negative effects on the feasibility of novel treatment approaches [23].

The high rate of patients who received systemic chemotherapy in this study $(91.7 \%)$ is obviously attributable to the advantages of free treatment services which are offered in all public hospitals across the country. As approximately half of the cases in the present study were diagnosed in advanced stages, the treatment was initiated with Anthracycline-based chemotherapy and the patients were monitored regularly by blood chemistry profiles and complete blood count tests. In those with hormone receptor positive tumors, $63.5 \%$ had Tamoxifen and/or Aromatase inhibitors as effective adjuvant endocrine therapy; while neoadjuvant hormone therapy was applied on nine patients who were not candidates for chemotherapy due to medical reasons. Due to the relatively high rate of HER2 positive breast cancer expressions among Iraqi patients observed in this study and others [3], [4], [7], [9], [36], [37], targeted biological therapy (Herceptin) was offered freely to $27 \%$ of the patients. These treatment protocols were almost in line with the recommendations of the breast health global guidelines for multidisciplinary integrated approaches to breast cancer management in limited resource settings [40], [45].

The relatively short period of follow-up in this study, compared to others [46]- [48], displayed a modest recurrence rate of breast carcinoma, in the form of local and regional relapses; that had significant direct association with the clinical stage of the disease at the time of diagnosis. It has been concluded that the most important factors associated with breast cancer recurrence are the size of the tumor and the axillary nodal involvement [47] whereas the clinical stage is considered predictive for estimating longterm survival [48].

In conclusion, breast carcinomas are still diagnosed at advanced stages at the time of initial presentation in Iraq; requesting radical mastectomies and palliative treatment. Early detection is the principal approach to control breast cancer in the near future. Multimodality treatment and long regular follow-up through multidisciplinary tumor boards are mandatory to monitor the response to therapy and avoid recurrence. Partnerships of cancer centers belonging to high income countries with those in limited resource nations could serve as a feasible approach to cancer control and research [49].

\section{CONFLICT OF INTEREST}

The authors declare that they have no conflict of interest that competes with any of the contents of the manuscript

\section{ACKNOWLEDGEMENT}

We thank gratefully the staff members of the Cancer Registry Section, National Cancer Research Center of Baghdad University and the professionals working at the Referral Center for Early Detection of Breast Tumors and the Oncology Department, Oncology Teaching Hospital of Baghdad Medical City.

\section{REFERENCES}

[1] Globocan 2018. World Health Organization. International Agency for Research on Cancer (IARC) Press. Geneva, Switzerland, 2018.

[2] Iraqi Cancer Board (2016). Results of the Iraqi Cancer Registry 2015. Baghdad, Iraqi Cancer Registry Center, Ministry of Health, 2018.

[3] Alwan N. Breast Cancer among Iraqi Women: Preliminary Findings from a Regional Comparative Breast Cancer Research Project. J Glob Oncol. 2016; 2(5): 255-258.

[4] Alwan, N, Kerr D, Al-Okati D, et al. Comparative study on the clinicpathological profiles of breast cancer among Iraqi and British patients. The Open Public Health Journal. 2018; (11): 177-191.

[5] Alwan NA, Tawfeeq FN, Maallah MH, et al. The Stage of Breast Cancer at the Time of Diagnosis: Correlation with the Clinicopathological Findings among Iraqi Patients. J Neoplasm. 2017; $2(3): 22$

[6] Alwan NAS, Tawfeeq FN, Mallah N. Demographic and clinical profiles of female patients diagnosed with breast cancer in Iraq. Journal of Contemporary Medical Sciences, 2019; 5 (1): 14-19.

[7] Alwan NAS. Tumor Characteristics of Female Breast Cancer: Pathological Review of Mastectomy Specimens Belonging to Iraqi Patients. World Journal of Breast Cancer Research, 2018; 1 (1): 1-3.

[8] Alwan NAS, Kerr D. Cancer Control in War-Torn Iraq, The Lancet Oncology, 2018; 19 (3): 291-292

[9] Alwan NAS, Tawfeeq FN. Comparison of Clinico-Pathological Presentations of Triple-Negative versus Triple-Positive and HER2 Iraqi Breast Cancer Patients. Open access Macedonian Journal of Medical Sciences, 2019; 7(21):3534-3539.

[10] Weigelt B, Baehner FL, Reis-Filho JS. The contribution of gene expression profiling to breast cancer classification, prognostication and prediction: a retrospective of the last decade. J Pathol. 2010; 220:263-280. 
[11] World Health Organization. Strategy for cancer prevention and control in the Eastern Mediterranean Region 2009-2013; World Health Organization. Regional Office for the Eastern Mediterranean, 2010.

[12] Alwan N. Iraqi Initiative of a Regional Comparative Breast Cancer Research Project in the Middle East, Journal of Cancer Biology \& Research, 2014; 2 (1): 1016 - 1020

[13] Alwan NAS, Al-Attar WM, Al Mallah N. Barriers to Baseline Needs for Early Detection of Breast Cancer among Iraqi Female Patients. Iraqi National Journal of Nursing Specialties, 2016; 29 (2): 1-11.

[14] Alwan N, al-Attar W, Eliessa R, Al-Midfaei Z \& Nidhal F:" Knowledge, Attitude and Practice regarding Breast Cancer and Breast Self-Examination among a Sample of the Educated Population in Iraq". EMHJ, WHO, EMRO, 2012; 18 (4): 337-345

[15] Al Alwan NAS and Mualla FHM: Promoting Clinical Breas Examination as a Screening Tool for Breast Cancer in Iraq. Iraqi National Journal for Nursing Specialties, 2014; 27 (1): 76-82.

[16] Al Alwan N: Establishing Guidelines for Early Detection of Breast Cancer in Iraq. Int. J. of Advanced Research. 2015.3 (12): 539-555

[17] Alwan N, Al-Diwan J, Al-Attar W \& Eliessa R: "Knowledge, Attitudes and Practice towards Breast Cancer and BSE in Kirkuk University, Iraq". Asian Pacific Journal of Reproduction, Elsevier, 2012; 1 (4): 308-311.

[18] Alwan NAS and Al-Attar: Evaluating the Effect of an Educational Teaching Model on the Knowledge about Breast Cancer among Female University Students in Iraq., JJ Cancer Sci. Res. 2016, 2 (1): 026

[19] Alwan NAS, Alattar W, Mallah N, Hassoun T: Baseline Needs Assessment for Breast Cancer Awareness and Management among Paramedical Health Care Providers in Iraq. International Journal of Science and Research (IJSR), 2017; 6 (7):1515-1520.

[20] Alwan NAS, Tawfeeq FN, Abdulsattar SY, Yihya F. Assessing the period between diagnosis of breast cancer and surgical treatment among mastectomized female patients. International Journal of Medical Research \& Health Sciences, 2019; 8 (1), 2019.

[21] Von Karsa L, Qiao Y, Ramadas K et al. Prevention/Screening Implementation, in Stewart BW and Wild CP (eds): World Cancer Report 2014. Lyon, France, World Health Organization International Agency for Research on Cancer, 2014

[22] Sankar R, Alwan N, Denny L. How Can We Improve Survival from Breast Cancer in Developing Countries?. Future Medicine, Breast Cancer Management, 2013, 2 (3): 179-183

[23] El Saghir N, Khalil MK, Eid T, et al. Trends in epidemiology and management of breast cancer in developing Arab countries: A literature and registry analysis. International Journal of Surgery, 2007; 226-233.

[24] Shulman LN, Willett W, Sievers A et al. Breast Cancer in Developing Countries: Opportunities for Improved Survival, Journal of Oncology, 2010; 1-6.

[25] Baccach J, Mansouri M, Derkaoui T et al. Clinicopathologic and prognostic features of breast cancer in young women: a seriesfrom North of Morocco. BMC Women's Health, 2017; 17:106

[26] Lakhani SR, Ellis IO, Schnitt SJ et al. WHO Classification of Tumours of the Breast. Fourth Edition, WHO Classification of Tumours, Volume 4, IARC, 2012.

[27] Elston CW, Ellis IO: Pathological prognostic factors in breast cancer. I. The value of histological grade in breast cancer: Experience from a large study with long-term follow-up. Histopathology, 2002; 41:154 161.

[28] Sobin LH, Gospodarowicz MK, Wittekind C. TNM Classification of Malignant Tumours. New York, NY, John Wiley \& Sons 2011.

[29] Alwan NAS: Family History among Iraqi Patents Diagnosed with Breast Cancer, IJSR, 2017; 6 (2): 868-872

[30] Chia KS, Reilly M, Tan CS, et al. Profound changes in breast cancer incidence may reflect changes into a Westernized lifestyle: a comparative population-based study in Singapore and Sweden, Int J Cancer, 2005; 113 (2): 302-306)

[31] Eleni L, Demetri Ss, Bernard A.et al. Effects of Reproductive and Demographic Changes on Breast Cancer Incidence in China: A Modeling Analysis, JNCI: Journal of the National Cancer Institute, 2008; 100 (19):1352-1360.

[32] Momenimovahed Z, Salehiniya H. Epidemiological characteristics of and risk factors for breast cancer in the world. Breast Cancer, 2019; 11:151-164.

[33] Erica T. Warner, Rulla M. Tamimi, Melissa E et al. Racial and Ethnic Differences in Breast Cancer Survival: Mediating Effect of Tumor Characteristics and Sociodemographic and Treatment Factors. Journal of Clinical Oncology, 2015; 33 (20): 2254-2261

[34] Min Yi, Peijun Liu, $\mathrm{Xu} \mathrm{Li}$ et al. Comparative Analysis of Clinicopathologic Features, Treatment, and Survival of Asian Women with a Breast Cancer Diagnosis Residing in the United States. Cancer, 2012: 1: 4117-4125

[35] Alwan NAS: Clinical and Pathological Characteristics of Familial Breast Cancer in Iraq, Chronicle Journal of Cancer Science, 2017; 1 (1): 002

[36] Alwan NAS, Mualla F, Naqash $M$ et al: Clinical and Pathological Characteristics of Triple Positive Breast Cancer among Iraqi Patients, Gulf Journal of Oncology, 2017; 25: 6-15.

[37] Alwan NAS, Tawfeeq FN, Muallah FH. Breast Cancer Subtypes among Iraqi Patients: Identified by Their ER, PR and HER2 Status. J Fac Med Baghdad, 2017; 59 (4): 304-307.

[38] Espina C, McKenzie F, Siva I. Delayed presentation and diagnosis of breast cancer in African women: a systematic review. Annals of Epidemiology, 2017; 27: 659-671.

[39] Talpur AA, Surahio AR, Ansari A. Late presentation of breast cancer: A Dilemma. J. Pak Med Assoc. 2011; 61 (7): 661-666.

[40] Echavarria MI, Anderson BO, Duggan C, Thompson B. Global uptake of BHGI guidelines for breast cancer. The Lancet Oncology, 2014; 15 (13): 1421-1423.

[41] Lazaraviciute G, Chaturvedi S. Mastectomy-A Critical Review. Open Journal of Clinical Diagnostics, 2017; 7: 58-66.

[42] Powell E, Joanne Chafe RN MN. Surgical treatment choices for breast cancer in Newfoundland and Labrador: a retrospective cohort study. Canadian Journal of Surgery. 2018; 1; 61(6):377.

[43] Onitilo, A.A., Engel, J.M., Stankowski, R.V. et al. Survival Comparisons for Breast Conserving Surgery and Mastectomy Revisited: Community Experience and the Role of Radiation Therapy. Clinical Medicine \& Research, 2015; 13: 65-73.

[44] Anthony FY, Yadav NU, Lung BY et al. Trastuzumab interruption and treatment-induced cardiotoxicity in early HER2-positive breast cancer. Breast Cancer Research and Treatment. 2015 Jan 1; 149 (2):489-95.

[45] Carlson RW, Anderson BO, Chopra R et al. Treatment of Breast Cancer in Countries with Limited Resources. The Breast Journal, 2003; 9 (2): 567-574

[46] Freedman GM, Fowble BL. Local Recurrence after Mastectomy or Breast-Conserving Surgery and Radiation. Oncology, 2000; 14 (11): 1561-1581.

[47] Lafourcade A, His M, Baglietto L et al. Factors associated with breast cancer recurrences or mortality and dynamic prediction of death using history of cancer recurrences. BMC cancer. 2018; 18 (1):171.

[48] Soerjomataram I, Louwman MW, Ribot JG et al. An overview of prognostic factors for long-term survivors of breast cancer. Breast Cancer Research and Treatment. 2008; 107 (3):309-30.

[49] Love RR: Defining a global research agenda for breast cancer Cancer. 2008; 113: 2366-2371.

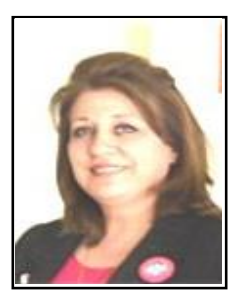

Principal Author: Prof. Dr. NADA A S Alwan (M.D. Ph.D.) Present Positions:

Adviser to the President of the Republic for Health Affairs, Presidency Office, Republic of Iraq (since August 2019).

Professor, Senior Researcher, Founder, National Cancer Research Center, University of Baghdad.

Scientific Supervisor, Consultant, National Program for Early Detection of Breast Cancer, Oncology Teaching Hospital.

Institutional Positions (undertaken before August 2019)

- $\quad$ Founding Director, National Cancer Research Center / Program Baghdad University, Ministry of Higher Education \& Scientific Research MoHESR (from 22 July 2012 - 7 August 2019)

- Professor of Pathology, Medical College, University of Baghdad (since 2001)

- Executive Director, National Campaign for Early Detection and Research on Breast Cancer (since 2010)

- Chairperson, Medical Committee, Iraqi Scientific Research Council, MoHESR (since 2012).

- Manager, Main Specialized Center for Early Detection of Breast Tumours, Oncology Teaching Hospital, (since 2003).

- Principal Investigator, Regional Comparative Breast Cancer Research Project (since 2012).

- National Project Coordinator, Capacity Building Project for Cancer Diagnisis and Treatment, IAEA

As a Professor of Pathology since 2001, she collaborated in organizing the National Program for Early Detection of Breast Cancer in Iraq and served as its Executive Director. In 2009, she established the "Iraqi National Breast Cancer Research Program. Following a visit to the Screening Unit of IARC (International Agency for Research on Cancer) in 
2010, she developed, with their assistance, a comprehensive online information system data base for Iraqi patients complaining of breast cancer; which was utilized later to compare the demographic characteristics, clinico-pathological presentations and management outcomes among patients affected with breast cancer in countries within the Eastern Mediterranean Region.

The author published 98 scientific articles in peer reviewed journals focusing on cancer burden in Iraq and the means of its control. In 2017, she worked as an Academic Visitor at Oxford University on a joint research project comparing the demographic and clinico-pathological profiles of breast cancer among Iraqi and British patients. Within the fields of adopting national cancer control strategies and establishing early detection programs, Prof. Alwan served as an international/regional expert and technical advisor to WHO/EMRO, IAEA Technical Cooperation Program, US Middle East Partnership Initiative, Suzan G Komen for the Cure and the Jordan National Breast Cancer Program. 